\title{
Diagnóstico da qualidade físico-química do solo sob diferentes usos e manejos no Sul de Minas Gerais
}

Cláudia Heluani de Sousa Antunes ${ }^{1}$

Leidiane Portugal ${ }^{2}$

João Paulo Maia ${ }^{3}$

Renata Amato Moreira ${ }^{4}$

Bruno Montoani da Silva 5

Walbert Júnior Reis dos Santos ${ }^{6}$

\section{Resumo}

Os diferentes sistemas de cultivo causam alterações nas propriedades do solo, com transformações em sua estrutura, que podem modificar sua qualidade. Com o propósito de analisar alterações nas propriedades físico-químicas sob diferentes usos da terra em Latossolo Vermelho-Amarelo e Argissolo Vermelho-Amarelo, avaliaram-se áreas de produção do IFSULDEMINAS, Campus Muzambinho. Os sistemas de cultivo avaliados foram lavoura cafeeira, monocultivo de milho, pastagem e mata nativa. Os parâmetros analisados foram: densidade do solo (Ds), estabilidade de agregados, teor de matéria orgânica (MO), pH e cálcio $\left(\mathrm{Ca}^{2+}\right)$. O delineamento experimental foi inteiramente casualizado com quatro tratamentos. Análise de variância foi realizada, sendo as médias dos diferentes tratamentos (uso do solo) comparadas pelo Teste Tukey e, quando significativas, ao Teste F. Os resultados obtidos demonstram aumento $(P<0,05)$ na Ds entre as áreas amostradas na camada de 5-10 $\mathrm{cm}$ sobre a área de pastagem. A estabilidade de agregados, expressa por meio do diâmetro médio geométrico (DMG), decresceu $(P<0,05)$ na área de monocultivo de milho, comparada aos demais usos. O teor de $\mathrm{MO}$ não diferiu $(\mathrm{P}>0,05)$ entre os tratamentos, tampouco correlacionou-se com 0 DMG. Houve correlação negativa $(r=-0,969$; $P<0,031)$ entre o DMG e Ca, DMG e pH $(r=-0,684$; $P<0,041$ ) se tratando da área em uso de pastagem. Assim, conclui-se que os diferentes sistemas de cultivo causam alterações nas propriedades do solo, podendo resultar em compactação e implicar o aumento da suscetibilidade à erosão.

Palavras-chave: Densidade do solo. DMG. Níveis de cálcio. Sistemas de manejo do solo.

\footnotetext{
1 Instituto Federal de Educação, Ciência e Tecnologia do Sul de Minas Gerais (IFSULDEMINAS), Campus Muzambinho, discente em Engenharia Agronômica. claudiaheluani@outlook.com; Estrada de Muzambinho, km 35, s/n, Bairro Morro Preto, Caixa Postal 02, CEP: 37.890-000, Muzambinho, MG, Brasil.

2 IFSULDEMINAS, Campus Muzambinho, discente em Engenharia Agronômica. leidiane.portugal@hotmail.com. 3 IFSULDEMINAS, Campus Muzambinho, discente em Engenharia Agronômica. joaopaulomaianr@gmail.com.

4 Universidade Federal de Lavras (UFLA), Departamento de Fitotecnia, engenheira agrônoma/mestranda em Fitotecnia. renata_amato@ hormail.com.

5 Universidade Federal de Lavras (UFLA), Departamento de Ciência do Solo (DCS), professor pesquisador. montoani@gmail.com.

6 IFSULDEMINAS, Campus Muzambinho, professor pesquisador. walbert.santos@ifsuldeminas.edu.br.
} 


\section{Introdução}

O Brasil possui elevada atividade agrícola e pecuária, sendo ambas responsáveis por importante sustentação da economia nacional. Apesar do arrefecimento da economia, o setor agropecuário seguiu em trajetória distinta à queda do PIB e subiu 1,8\% em 2015. A expressiva atividade agropecuária no PIB, de 4,46\% a preços correntes em 2015, apesar de parecer pouco, trouxe influência relevante para o desempenho econômico do país (COMPANHIA NACIONAL DE ABASTECIMENTO - CONAB, 2016).

Nestas atividades são observadas a adoção de vários sistemas de uso e manejo do solo. Agricultores e pecuaristas são os responsáveis pela adoção dos diferentes sistemas, ficando a cargo dos profissionais da área sua avaliação e consequente sugestão de aplicação de estratégias para o uso sustentável (BILIBIO; CORRÊA; BORGES, 2010).

As práticas de manejo adotadas no desenvolvimento das atividades agropecuárias ocasionam importantes mudanças na qualidade física do solo, a qual pode ser constatada, por exemplo, pela estabilidade dos agregados e pela densidade do solo (Ds), entre outros fatores considerados indicadores da qualidade do solo (BISWAS et al., 2017). De acordo com Sá et al. (2000), a estabilidade de agregados é o fator que mais se correlaciona com a suscetibilidade do solo à erosão. Sua alteração para índices menores afeta negativamente a infiltração, retenção de água, aeração e resistência de penetração das raízes, resultando em maior suscetibilidade a perdas de solo e em compactação devido à baixa resistência mecânica (REICHERT; REINERT; BRAIDA, 2003).

Pesquisas demonstram que a intensificação do uso do solo, o elevado peso das máquinas agrícolas utilizadas e a superlotação de animais (superpastejo), ou seja, diferentes atividades agropecuárias levam a alterações significativas, geralmente desfavoráveis, nas propriedades físico-químicas do solo (CAVALIERI et al. 2006). Tais alterações são mais significativas principalmente quando realizadas por um longo período de tempo, afetando a qualidade da terra (FREDDI et al., 2007). Entre essas alterações podemos citar a compactação do solo, o surgimento de processos erosivos (COSTA et al., 2008), a diminuição dos teores de matéria orgânica (MO), nutrientes (CREMON et al., 2009), entre outras.

Em solos ácidos de regiões tropicais e subtropicais a calagem é prática comum de manejo da fertilidade do solo, sendo associada indiretamente ao aumento do rendimento das culturas (ALBUQUERQUE et al., 2000). A elevação do pH tem influência positiva na atividade microbiana, disponibilidade de fósforo $(P)$ e redução da fitotoxidez do alumínio $(A l)$ e manganês $(\mathrm{Mn})$, repercutindo na absorção de nutrientes (ERNANI et al., 1998). Em contrapartida, a calagem altera alguns atributos de natureza eletroquímica e física de solos muito intemperizados.

Os agregados, por meio de diferentes agentes cimentantes, unem-se sucessivamente no solo originando agregados de maior complexidade e, consequentemente, maior tamanho (SILVA NETO et al., 2010). Nesse contexto, de acordo com a formação pedogênica de agregados com predominância de cátions monovalentes no complexo de troca, o efeito do cálcio $\left(\mathrm{Ca}^{2+}\right)$ será agregante. Por outro lado, quando predominam cátions trivalentes, o efeito do $\mathrm{Ca}^{2+}$ é de provocar a dispersão (MORELLI; FERREIRA, 1987).

Considerando a estreita relação dos diferentes usos da terra com a qualidade física do solo, objetivou-se, com a realização deste trabalho, estudar a Ds, estabilidade de agregados, teor de $\mathrm{MO}, \mathrm{pH}$ e $\mathrm{Ca}^{2+}$ em Latossolo Vermelho-Amarelo e Argissolo Vermelho-Amarelo, sob influência de diferentes cultivos. 


\section{Material e métodos}

O presente estudo foi conduzido em áreas de produção no Instituto Federal de Educação, Ciência e Tecnologia do Sul de Minas Gerais (IFSULDEMINAS), Campus Muzambinho (MG), situado na latitude $21^{\circ} 20^{\prime} 47^{\prime \prime}$ Sul e longitude 4632'04" Oeste, com altitude média de 1.033 metros, durante agosto de 2015 a julho de 2016. O clima do local é classificado como Cwb, temperado úmido, segundo a classificação de Köppen, com inverno seco e verão moderadamente quente (SÁ JúNIOR et al., 2012). A precipitação acumulada foi de $1.790,5 \mathrm{~mm}$ e 1.652,2 $\mathrm{mm}$ nos anos de 2015 e 2016 , respectivamente, valores esses considerados dentro da normalidade climatológica e temperatura média anual de $18^{\circ} \mathrm{C}$ (APARECIDO; SOUZA, 2015; 2016).

Foram estudadas quatro áreas com diferentes usos, sendo uma área em lavoura experimental cultivada com café (A1) avaliada na linha de plantio $A 1$ a e entrelinha $A 1 b$, área de produção de milho (A2), área de pastagem (A3) e área de mata nativa (A4), esse último uso utilizado como referência nas comparações. A Tabela 1 apresenta o histórico de uso e manejo das áreas e a Tabela 2 a classificação e características físicas dos solos.

Tabela 1. Características de uso e manejo do solo das áreas usadas neste estudo.

\begin{tabular}{|c|c|}
\hline Áreas de avaliação & Características \\
\hline $\mathrm{A} 1$ & $\begin{array}{l}\text { - Lavoura de café - Coffea arabica L., cultivar Catuaí Amarelo; } \\
\text { - Área: 0,067 hectares, espaçamento de 2,5 metros (entre linhas) × 1,0 metro } \\
\text { (entre plantas); } \\
\text { - Implantação: } 2011 \text { com preparo convencional do solo (aração e gradagem); } \\
\text { - Atividades de manejo convencionais realizadas manualmente; } \\
\text { - Utilização de braquiária nas entre linhas como planta de cobertura; } \\
\text { - Com base na análise de solo na última aplicação (2015) dispensou-se a calagem } \\
\text { (V\% 67,4) e fósforo; } \\
\text { - Realizada adubação com NPK (25-00-25) - } 150 \text { g planta-1; } \\
\text { - Classificação do solo: Latossolo Vermelho-Amarelo Distrófico. }\end{array}$ \\
\hline A2 & $\begin{array}{l}\text { - Milho em monocultivo; híbrido } 30 f 53 \text { - Pionner } \\
\text { - Área: 4,0 hectares, espaçamento de 0,6 metros (entre linhas) × 0,6 metros (entre } \\
\text { plantas); } \\
\text { - Implantação do monocultivo: } 2011 \text { com preparo convencional do solo (aração e } \\
\text { gradagem); } \\
\text { - Plantio todo o ano sem revolvimento e subsolagem }(30 \mathrm{~cm}) \text { a cada quatro anos; } \\
\text { - Atividades de manejo realizadas com uso de maquinário especializado; } \\
\text { - Classificação do solo: Latossolo Vermelho-Amarelo Distrófico. }\end{array}$ \\
\hline A3 & $\begin{array}{l}\text { - Pastagem - vegetação composta por Brachiaria decumbens implantada há } 28 \text { anos, } \\
\text { relevo forte ondulado e declividade média de } 30 \% \text {; } \\
\text { - Área: 0,95 hectares amostrados de um total de } 7 \text { hectares; } \\
\text { - Atividades de manejo: pastejo contínuo e sistema extensivo de bovinos, sem controle } \\
\text { de lotação; } \\
\text { - Histórico: há } 20 \text { anos foram aplicadas } 26 \text { toneladas de gesso e há } 5 \text { anos o solo } \\
\text { foi preparado com manejo convencional (aração e gradagem) e curvas de nível } \\
\text { renovadas; } \\
\text { - Classificação do solo: Argissolo Vermelho-Amarelo Distrófico. }\end{array}$ \\
\hline A4 & $\begin{array}{l}\text { Mata nativa; } \\
\text { Classificação do solo: Argissolo Vermelho-Amarelo Distrófico. }\end{array}$ \\
\hline
\end{tabular}

A1: Cultivo de café; A2: Cultivo de milho; A3: Pastagem; A4: Mata nativa.

Fonte: Elaborado pelos autores (2017). 
Tabela 2. Classes de solo, horizontes do solo $(\mathrm{H})$, profundidade dos horizontes, granulometria e textura.

\begin{tabular}{|c|c|c|c|c|c|c|c|}
\hline \multirow{2}{*}{ Uso $^{1}$} & \multirow{2}{*}{ Classe $^{2}$} & \multirow{2}{*}{ Horizonte } & \multirow{2}{*}{$\begin{array}{l}\text { Profundidade } \\
\quad(\mathrm{cm})\end{array}$} & \multicolumn{3}{|c|}{$\begin{array}{l}\text { Granulometria } \\
\left(\mathrm{g} \mathrm{kg}^{-1}\right)\end{array}$} & \multirow{2}{*}{ Textura } \\
\hline & & & & Areia & Silte & Argila & \\
\hline \multirow{2}{*}{$\mathrm{A} 1$} & \multirow{2}{*}{ LVAd } & A & $0-20$ & 400 & 80 & 520 & argilosa \\
\hline & & Bw & $30-120$ & 390 & 100 & 510 & argilosa \\
\hline \multirow{2}{*}{$\mathrm{A} 2$} & \multirow{2}{*}{ LVAd } & A & $0-18$ & 310 & 190 & 500 & argilosa \\
\hline & & Bw & $36-120$ & 250 & 100 & 650 & argilosa \\
\hline \multirow{2}{*}{ A3 } & \multirow{2}{*}{ PVAd } & A & $0-15$ & 380 & 115 & 470 & argilosa \\
\hline & & $\mathrm{Bt}$ & $15-80$ & 310 & 120 & 570 & argilosa \\
\hline \multirow{2}{*}{ A4 } & \multirow{2}{*}{ PVAd } & A & $0-20$ & 660 & 90 & 250 & média \\
\hline & & $\mathrm{Bt}$ & $40-80$ & 480 & 70 & 450 & argilosa \\
\hline
\end{tabular}

${ }^{1}$ A1: Cultivo de café; A2: Cultivo de milho; A3: Pastagem; A4: Mata nativa.

2LVAd: Latossolo Vermelho-Amarelo Distrófico; PVAd: Argissolo Vermelho-Amarelo Distrófico.

Fonte: Santos et al. (2013).

Para as avaliações dos atributos físicos do solo foram coletadas amostras com estrutura indeformada em quatro pontos aleatórios para cada sistema de manejo. Na determinação da Ds utilizou-se de anel volumétrico de $77,78 \mathrm{~cm}^{3}$ nas profundidades de 0-5 e 5-10 e no ponto médio da camada de $10-20 \mathrm{~cm}$. Seguindo a metodologia, a massa de sólidos coletada em volume conhecido foi levada para estufa por 24 horas à temperatura de $105^{\circ} \mathrm{C}$ até atingir peso constante. A seguir, quantificou-se a massa de solo seco para determinação da Ds, por meio da equação 1 .

$\mathrm{Ds}=\mathrm{Ms} / \mathrm{V}$

em que:

Ms: massa de solo seco

V: volume do anel volumétrico

Foram coletados monólitos de solo da camada de $0-20 \mathrm{~cm}$, com quatro repetições por manejo, nos quais foi utilizado o método de peneiramento úmido descrito pela Embrapa (2011) para obtenção dos agregados e determinação da estabilidade desses. Para a lavoura cafeeira, a amostragem foi efetuada apenas na projeção da copa. As análises de estabilidade de agregados foram realizadas no Laboratório de Física e Conservação do Solo da Universidade Federal de São João del-Rei, Campus Sete Lagoas.

O solo amostrado foi fracionado, observando-se os pontos de fraqueza. Após secagem, os monólitos foram transpassados em peneiras de 8,00 e 4,75 milímetros. 0 solo retido na peneira de 4,75 $\mathrm{mm}$ foi pesado, constituindo 25 gramas de amostra em placas de Petri, e pré-umedecidos por capilaridade com auxílio de papel-filtro. A separação dos agregados em classes de tamanho (2,0; 1,0; 0,5; 0,25 e 0,105 mm) foi feita pela desagregação e peneiramento em meio úmido, utilizando agitador mecânico tipo Yoder. Os agregados obtidos em cada classe de tamanho foram secos em estufa a 110 
${ }^{\circ} \mathrm{C}$ e pesados. Os resultados foram expressos em porcentagem. Como índice de agregação, adotou-se o diâmetro médio geométrico (DMG) obtido conforme Mazurak (1950) por meio da equação 2.

$$
\mathrm{DMG}=10^{\wedge} \sum(n \log d) \div \sum n
$$

em que:

$\mathrm{n}$ : porcentagem de agregados em cada classe de tamanho

d: diâmetro médio da classe de agregados

Para a determinação de $\mathrm{Ca}, \mathrm{MO}$, pH e textura foram encaminhadas amostras ao Laboratório de Análise de Solo e Tecido Vegetal do IFSULDEMINAS, Campus Muzambinho, conforme metodologia da Embrapa (2011).

O delineamento experimental foi inteiramente casualizado (DIC) em esquema fatorial $4 \times 3$ (quatro usos da terra $\times$ três profundidades de amostragem), com quatro tratamentos (A1, A2, A3 e A4) e quatro repetições por tratamento. Os dados (DMG, Ds, MO, pH e cálcio) são apresentados como média \pm desvio-padrão (DP).

Após o teste de normalidade dos resíduos (Shapiro-Wilk) e homocedasticidade das variâncias (Levene), a análise de variância (ANOVA) foi realizada, sendo as médias dos diferentes tratamentos (uso do solo) e das diferentes profundidades comparadas pelo Teste Tukey e, quando significativas, pelo Teste F. Correlações lineares de Pearson entre DMG e MO assim como com o teor de $\mathrm{Ca}$ e $\mathrm{pH}$ foram realizadas.

Um nível de significância de $5 \%$ foi considerado como indicativo de diferença significativa. Toda análise estatística foi realizada utilizando o pacote estatístico IBM ${ }^{\circledR}$ SPSS for Windows ${ }^{\circledR}$, versão 20.0.0 (IBM $\left.{ }^{\circledR}, 2012\right)$.

\section{Resultados e discussão}

Os usos do solo avaliados diferiram $(P<0,05)$ em relação a Ds, notadamente na camada de 5-10 cm (TABELA 3). Tendo em vista os valores de referência sob mata nativa, verifica-se nessa profundidade que o valor mais alto para a Ds foi observado na área sob pastagem. Isto pode ser explicado pelo efeito do pisoteio do gado. 


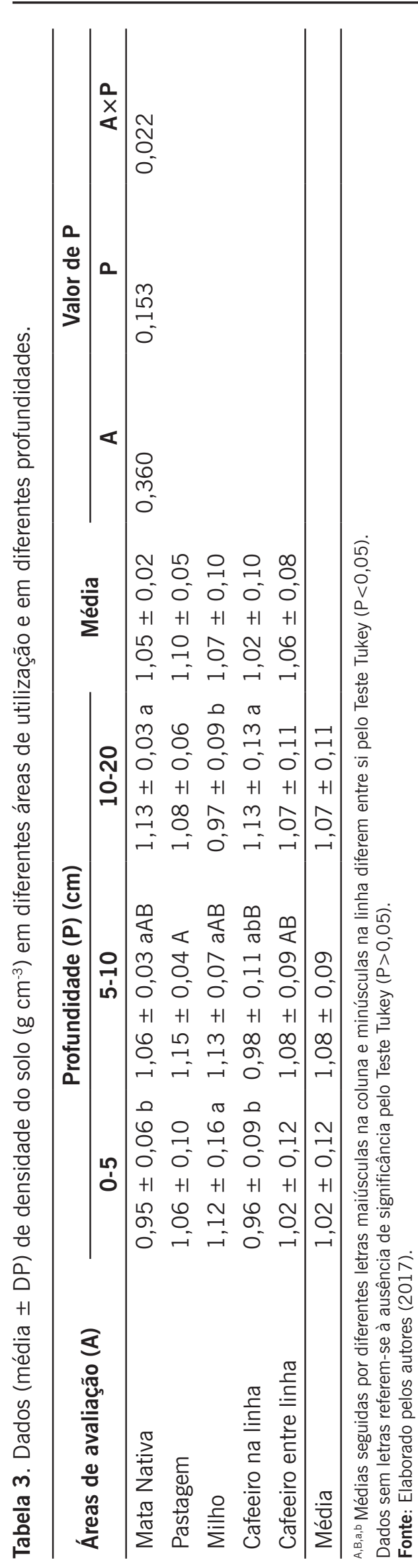


A Ds de 1,15 $\mathrm{g} \mathrm{cm}^{-3}$ observada não caracteriza compactação, uma vez que o limite crítico de Ds é $1,21 \mathrm{gcm}^{-3}$ para solos da classe textural argilosa, o que restringe o alongamento da raiz (REYNOLDS et al., 2002). Adicionalmente à grande produção de biomassa vegetal na superfície do solo e principalmente pela intensa renovação do sistema radicular abundante e permanente, a área de pastagem possui elevada capacidade de acúmulo da MO, não diferida da mata (FIGURA 1), agindo na manutenção dos atributos físicos do solo (GAZOLLA et al., 2015).

Figura 1. Dados de dispersão e correlação entre o Diâmetro Médio Geométrico (DMG) e Cálcio (Ga); entre DMG e pH ( $\underline{\mathrm{Gb}})$ e entre DMG e Matéria Orgânica $(\underline{\mathrm{Gc}})$.

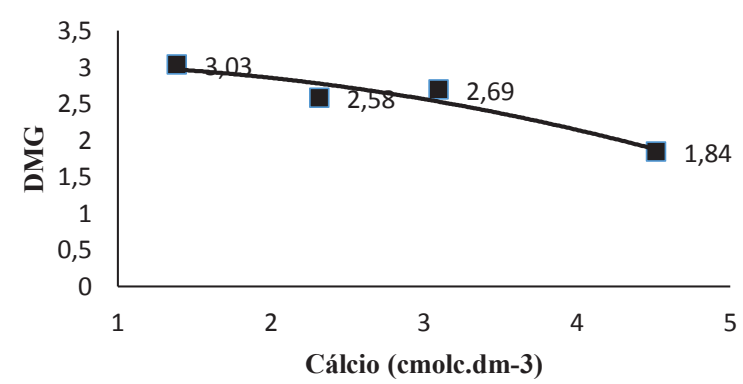

Gb

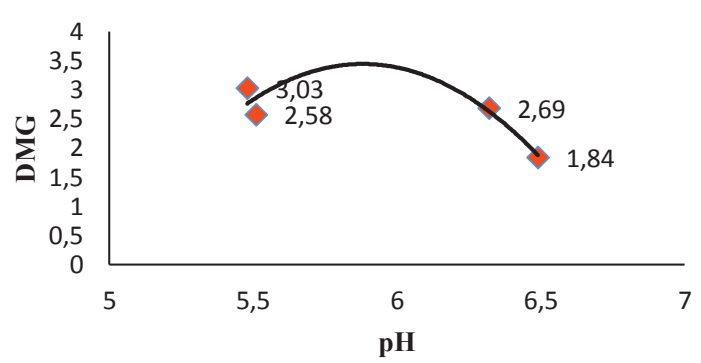

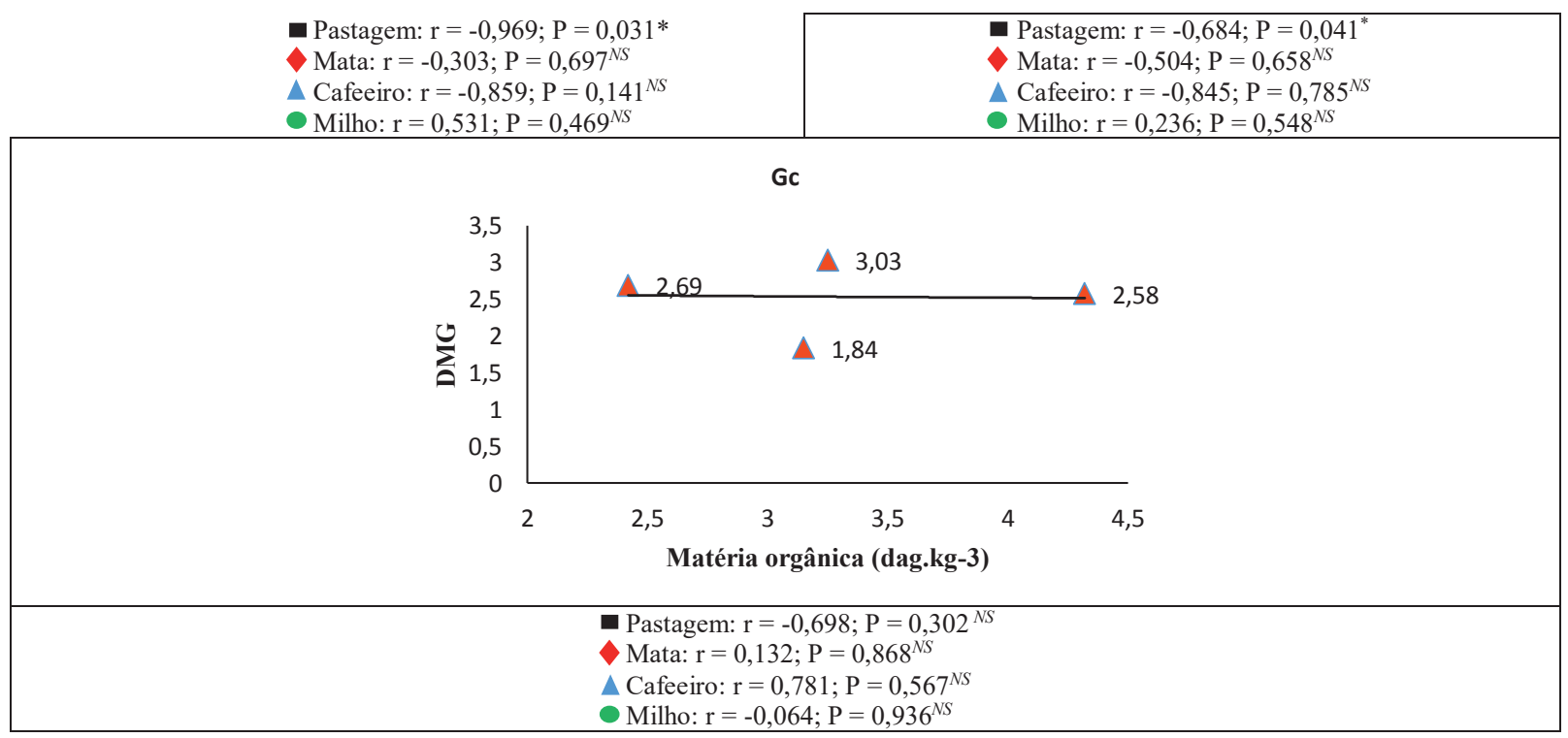

a,b,A,B,CLetras minúsculas referem-se a diferenças pelo Teste Tukey $(P<0,05)$ para a variável DMG (eixo y) e letras maiúsculas referem-se a diferenças pelo Teste Tukey $(\mathrm{P}<0,05)$ para as variáveis $\mathrm{Ca}^{2+}$, $\mathrm{pH}$ e $\mathrm{MO}$ e em todos os gráficos (eixo x).

Fonte: Elaborado pelos autores (2017).

0 maior DMG $(P<0,05)$ observado foi na área de pastagem, demonstrando que mesmo com maior Ds comparada aos outros usos, a pastagem possui maior resistência à erosão (FIGURA 1). Deste modo, quanto menor o revolvimento do solo, maior é a sua capacidade de agregação. Spera et al. (2009), citados por Melloni, Melloni e Vieira (2013), corroboraram essa afirmação ao estudarem pastagens perenes e pastagens/lavouras anuais. 
Houve correlação negativa ( $r=-0,969 ; \mathrm{P}<0,031)$ entre o DMG e o nível de cálcio do solo utilizado para pastagem. Isso pode ser explicado pela aplicação do calcário em menor quantidade. Assim, o menor aporte de $\mathrm{Ca}^{2+}$ implicou permanência de Al. Esse último é muito importante na floculação da argila, portanto, na agregação do solo. Ademais, a correlação negativa $(r=-0,684 ; P<0,041)$ entre 0 DMG e o pH reflete a diminuição da hidratação das partículas em função da substituição do $\mathrm{H}^{+}$por $\mathrm{Ca}^{2+}$ no complexo de troca, favorecendo a floculação (FIGURA 1) (FONTES et al., 1995).

Rosa Junior et al. (2006), ao estudarem o efeito do uso de calcário em pastagens e culturas anuais, verificaram que seu uso para elevar a saturação por bases a $100 \%$ produziu efeitos inversos e proporcionais para os valores de grau de floculação. Os autores sugeriram que isso pode ter ocorrido em função dos maiores valores obtidos para pH sob essas condições.

Verificaram-se correlações negativas entre DMG e cálcio, DMG e pH para os usos mata e cafeeiro e positivas para milho; entretanto, todas não significativas ( $P>0,05)$ (FIGURA 1$)$. Entre os diferentes usos foi registrado que os valores de $M O$ não diferem entre si $(P>0,05)$, portanto, não houve correlação ( $P>0,05)$ entre DMG e MOS (FIGURA 1), demonstrando que a intensidade, tempo e cobertura de cada uso contribuíram para a sua reposição. Ademais, por estar em uma região de altitude, o clima ameno pode ter contribuído para a manutenção da MO. Ellsworth, Clapp e Blake (1991), ao avaliarem a variabilidade temporal na estrutura do solo sob cultivo de milho e soja, ressaltam que tal influência das práticas de manejo sobre a estrutura do solo é complexa e requer amostragem durante vários ciclos.

Independente do uso e sistema de manejo adotado, na profundidade de $0-5 \mathrm{~cm}$, os menores valores de Ds foram observados, exceto para a área de milho (TABELA 3). Isso pode ser decorrente da menor exposição de camadas mais profundas à ação de microrganismos decompositores da MOS associado ao menor aporte (GAZOLLA et al., 2015). Na área de milho, a menor Ds foi verificada na profundidade de $10-20 \mathrm{~cm}$, podendo ser resultado da subsolagem efetuada na área a cada quatro anos.

Foram registradas diferenças significativas $(P<0,05)$ entre as profundidades para a mesma área na Ds, ao menos para os usos pastagem e café entre linha. Tais resultados apontam que os efeitos desses usos foram similares até a profundidade de $20 \mathrm{~cm}$ (TABELA 3).

As diferentes posições de amostragem na cultura do cafeeiro quando comparadas mostraram-se não significativas $(p>0,05)$. Como se esperava haver diferença entre as posições no sistema de manejo, o resultado reflete que esse atributo não foi pertinente para quantificar o efeito do manejo na estrutura do solo, corroborando Carmo et al. (2011). Esse fato pode ser decorrente do recente estabelecimento da cultura não provocando modificações nesse atributo físico do solo, além de ter a maior parte dos manejos de forma manual.

Para a mata nativa, a maior Ds $(P<0,05)$ nas camadas de $5-10 \mathrm{~cm}$ e $10-20 \mathrm{~cm}$, quando comparada à de $0-5 \mathrm{~cm}$, deve-se provavelmente à maior deposição de $\mathrm{MO}$ na superfície do solo e também à estrutura em blocos nessa camada, deixando-a mais densa, em contrapartida à estrutura grumosa da camada superior. A mesma situação foi observada na área de café amostrada na linha, em que a menor densidade da camada superior é, possivelmente, resultante da liberação de exsudatos orgânicos pelas raízes das plantas que também atuam como agentes de agregação e aos fatores supracitados (TABELA 3) (HARRIS et al., 1966).

A agregação do solo, por meio do DMG, no cafeeiro $(2,69 \mathrm{~mm})$ foi equivalente à verificada na mata nativa $(2,58 \mathrm{~mm}$ ), assim como para os valores médios de Ds (TABELA 3), demonstrando não degradação de sua qualidade, a qual está relacionada com as formas de manejo do cafeeiro, corrobo- 
rando Theodoro et al. (2003) que, ao avaliarem as mudanças químicas e físicas em solo submetido a diferentes sistemas de manejo do cafeeiro, verificaram que a Ds não diferiu entre os manejos de café $\left(1,22 \mathrm{~g} \mathrm{~cm}^{-3}\right)$ e a Ds da vegetação natural.

A área de monocultivo de milho apresentou menor ( $P<0,05)$ DMG $(1,84 \mathrm{~mm})$ comparada aos demais usos. A subsolagem realizada na área aliada às atividades de manejo e colheita por máquinas contribuem para a desagregação do solo. De acordo com Araújo, Goedert e Lacerda (2007), a estabilidade de agregados diminui à medida que o manejo é intensificado.

De acordo com Salton et al. (2008), sistemas de manejo do solo com pastagens permanentes ou em rotação com lavoura em plantio direto favorecem a formação de agregados estáveis de maior tamanho em relação a sistemas apenas com lavouras. Tais dados confirmam o encontrado no presente estudo, no qual menor estabilidade foi verificada na lavoura de milho em monocultivo e maior DMG $(3,03 \mathrm{~mm})$ em pastagens perenes.

\title{
Conclusões
}

A área sob pastagem apresentou aumento na Ds, na camada de $5-10 \mathrm{~cm}$, quando comparada aos demais sistemas de cultivo avaliados. Assim, sugere-se esse ser o uso que mais implica compactação.

$\mathrm{O}$ uso intenso do solo, sob monocultivo de milho, apresentou menor estabilidade de agregados. Tal fato elucidou o feito negativo do preparo convencional do solo sob o risco de erosão.

\section{Agradecimentos}

Ao Instituto Federal de Educação, Ciência e Tecnologia do Sul de Minas Gerais (IFSULDEMINAS), Campus Muzambinho, pela concessão da Bolsa Institucional de Iniciação Científica às autoras Cláudia e Leidiane (Edital n 01/2015) e pelo apoio financeiro na execução do projeto. À Universidade Federal de São João del-Rei (UFSJ), Campus Sete Lagoas, pelo auxílio na realização de análises do projeto.

\section{Diagnosis of the physical-chemical quality of the soil under different uses and management in the South of Minas Gerais}

\begin{abstract}
Different cropping systems cause changes in soil properties, with transformations in the structure of soil, which can modify its quality. Aiming to analyze changes in physical-chemical properties under different land uses in Red-Yellow Latosol and Red-Yellow Argisol, production areas of IFSULDEMINAS, Muzambinho Campus, were evaluated. The evaluated cropping systems were coffee plantations, maize monoculture, pasture and native forest. Soil density (Sd), aggregate stability, organic matter content $(\mathrm{OM}), \mathrm{pH}$ and calcium $(\mathrm{Ca} 2+)$ were the parameters analyzed. Experimental design was completely randomized with four treatments. Analysis of variance was performed and means of the different treatments (land use) were compared by Tukey Test and when significant to F Test. Results showed an increase $(P<0.05)$ in the $S d$ in the evaluated areas compared with the pasture area for the $5-10 \mathrm{~cm}$ layer. The aggregates stability, expressed by means of geometric mean diameter $(G M D)$, decreased $(P<0.05)$ for the maize monoculture area compared to other land uses. The OM
\end{abstract}


content did not differ $(P>0.05)$ between the treatments nor did it correlate to GMD. There was a negative correlation $(r=-0.969, \mathrm{P}<0.031)$ between GMD and $\mathrm{Ca} 2+$ and between GMD and $\mathrm{pH}(r$ $=-0.684, \mathrm{P}<0.041$ ) when dealing with the area under pasture. Therefore, it is concluded different cropping systems cause changes in soil properties which may result in compaction and increased susceptibility to erosion.

Keywords: Soil density. GMD. Levels of calcium. Soil management systems.

\section{Referências}

ALBUQUERQUE, J. A.; BAYER, C.; ERNANI, P. R.; FONTANA, E. C. Propriedade físicas e eletroquímicas de um latossolo bruno afetadas pela calagem. Revista Brasileira de Ciência do Solo, Viçosa, v. 24, n. 2, p. 295-300, 2000. Disponível em:<http://www.scielo.br/scielo.php?pi$\mathrm{d}=$ S0100-06832000000200006\&script=sci_abstract\&tlng=pt >. Acesso em: 01 nov. 2017.

APARECIDO, L. E. O.; SOUZA, P. S. Boletim Climático nº 29-33, dez. 2015.

APARECIDO, L. E. O.; SOUZA, P. S. Boletim Climático n 34-40. Muzambinho, dez. 2016.

ARAÚJO, R.; GOEDERT, W. J.; LACERDA, M. P. C. Qualidade de um solo sob diferentes usos e sob cerrado nativo. Revista Brasileira de Ciência do Solo, Viçosa, v. 31, n. 5, p. 1099-1108, 2007. Disponível em: <http://www.scielo.br/scielo.php?pid=S0100-06832007000500025\&script=sci_abstract\&tIng =pt>. Acesso em: 01 nov. 2017.

BILIBIO, W. D.; CORREAA, G. F.; BORGES, E. N. Atributos físicos e químicos de um latossolo, sob diferentes sistemas de cultivo. Ciência \& Agrotecnologia, Lavras, v. 34, n. 4, p. 817-822, jul./ago. 2010. Disponível em: http://www.scielo.br/scielo.php?pid=S1413-70542010000400004\&script=sci_ abstract\&tlng=pt. Acesso em: 05 nov. 2017.

BISWAS, S.; HAZRA, G. C.; PURAKAYASTHA, T. J.; SAHA, N.; MITRAN, T.; ROY, S. S.; BASAK, N.; MANDAL, B. Establishment of critical limits of indicators and indices of soil quality in rice-rice cropping systems under different soil orders. Geoderma, v. 292, p. 34-48, Apr. 2017. Disponível em: <https://www.sciencedirect.com/science/article/pii/S0016706117300101 >. Acesso em: 30 out. 2017.

CARMO, D. L. do; NANNETTI, D. C.; DIAS JÚNIOR, M. S.; SANTO, D. J. E.; NANNETTI, A. N.; LACERDA, T. M. Propriedades físicas de um Latossolo Vermelho-Amarelo cultivado com cafeeiro em três sistemas de manejo no sul de Minas Gerais. Revista Brasileira de Ciência do Solo, Viçosa, v. 35, n. 3, p. 991-998, 2011. Disponível em: <http://www.scielo.br/scielo.php?pi$\mathrm{d}=$ S0100-06832011000300033\&script=sci_abstract\&tIng=pt $>$. Acesso em: 27 nov. 2017

CAVAliERI, K. M. V.; TORMENA, C. A.; VIDIGAL FILHO, P. S.; GONÇALVES, A. C. A.; COSTA, A. C. S. da. Efeitos de sistemas de preparo nas propriedades físicas de um Latossolo Vermelho Distrófico. Revista Brasileira de Ciência do Solo, Viçosa, v. 30, n. 1, p. 137-147, jan./fev. 2006. Disponível em: $<$ http://www.scielo.br/scielo.php?script=sci_arttext\&pid=S0100-06832006000100014 >. Acesso em: 06 nov. 2017. 
COMPANHIA NACIONAL DE ABASTECIMENTO - CONAB. Perspectivas para a agropecuária - Safra 2016/2017. Perspectiva Agropecuária, Brasília, v. 4, p. 1-129, set. 2016. Disponível em: < https:// www.conab.gov.br/perspectivas-para-a-agropecuaria >. Acesso em: 06 nov. 2017.

COSTA, F. S.; BAYER, C.; ZANATTA, J. A.; MIELNICZUK, J. Estoque de carbono orgânico no solo e emissões de dióxido de carbono influenciadas por sistemas de manejo no sul do Brasil. Revista Brasileira de Ciência do Solo, Viçosa, v. 32, n. 1, p. 323-332, jan./fev. 2008. Disponível em: < http:// www.scielo.br/scielo.php?script $=$ sci arttext\&pid $=$ S0100-06832008000100030 > . Acesso em: 05 nov. 2017.

CREMON, C.; ROSA JÚNIOR, E. J.; SERAFIM, M. E.; ONO, F. B. Análise micromorfométrica de agregados de um Latossolo Vermelho Distroférrico sob diferentes sistemas de manejo. Acta Scientiarum. Agronomy, Maringá, v. 31, n. 1, p. 139-146, 2009. Disponível em: <http://www.scielo. br/scielo.php?pid=S1807-86212009000100021\&script=sci abstract\&tlng=pt>. Acesso em: 06 nov. 2017.

EMPRESA BRASILEIRA DE PESQUISA AGROPECUÁRIA - EMBRAPA. Centro Nacional de Pesquisa de Solos. Manual de métodos de análise de solo. 2. ed., Brasília: Embrapa, 2011. 212p. Disponível em: < https://www.infoteca.cnptia.embrapa.br/bitstream/doc/990374/1/ManualdeMtodosdeAnilisedeSolo.pdf > . Acesso em: 06 jun. 2016.

ELLSWORTH, T. R.; CLAPP, C. E.; BLAKE, G. R. Temporal variations in soil structural properties under corn and soybean cropping. Soil Science, v. 151, p. 405-416, june, 1991. Disponível em: < https://journals.Iww.com/soilsci/Abstract/1991/06000/Temporal Variations in Soil Structural Properties.2.aspx>. Acesso em: 05 nov. 2017

ERNANI, P. R.; NASCIMENTO, J. A. L.; OLIVEIRA, L. C. Increase of grain and green matter of corn by liming. Revista Brasileira de Ciência do Solo, Viçosa, v. 22, n. 2, p. 275-280, apr./jun. 1998. Disponível em: <http://www.scielo.br/pdf/rbcs/v22n2/13.pdf>. Acesso em: 07 nov. 2017.

FREDDI, O. S.; CENTURION, J. F.; BEUTLER, A. N.; ARATANI, R. G.; LEONEL, C. L. Compactação do solo no crescimento radicular e produtividade da cultura do milho. Revista Brasileira de Ciência do Solo, Viçosa, v. 31, n. 4, p. 627-636, 2007. Disponível em: < http://www.scielo.br/pdf/rbcs/ v31n4/a03v31n4>. Acesso em: 08 nov. 2017.

FONTES, M. P. F.; GJORUP, G. B.; ALVARENGA, R. C.; NASCIF, P. G. S. Calcium Salts and Mechanical Stress Effects On Water-Dispersible Clay of Oxisols. Soil Science Society of American Journal, Madison, v. 59, n. 1, p. 224-227, 1995.

GAZOLLA, P. R.; GUARESCHI, F. R.; PERIN, A.; PEREIRA, M. G.; ROSSI, C. Q. Frações da matéria orgânica do solo sob pastagem, Sistema plantio direto e integração lavoura-pecuária. Semina: Ciências Agrárias, Londrina, v. 36, n. 2, p. 693-704, mar./abr. 2015. Disponível em: <http://www.uel. br/revistas/uel/index.php/semagrarias/article/download/16159/16108>. Acesso em: 03 nov. 2017.

HARRIS, R. F.; CHESTERS, G.; ALLEN, O. N. Dynamics of soil aggregation. Advances in Agronomy, San Diego, v. 18, n. 1, p. 107-169, 1966. Disponível em: < https://www.sciencedirect.com/science/ article/pii/S0065211308606495>. Acesso em: 05 nov. 2017. 
IBM $^{\circledR}$ Corp. Released. SPSS ${ }^{\circledR}$ Statistics for Windows. Version 20.0, Release 20.0.0. Armonk, New York: IBM Corp., 2012.

MAZURAK, A. P. Effect of gaseous phase on water-stable synthetic aggregates. Soil Science, v. 69, n. 2, p. 135-148, feb. 1950. Disponível em: <https://journals.Iww.com/soilsci/Citation/1950/02000/ Effect_of_Gaseous_Phase_on_Water_Stable_Synthetic.5.aspx>. Acesso em: 06 nov. 2017.

MELLONI, R.; MELLONI, E. G. P.; VIEIRA, L. L. Uso da terra e a qualidade microbiana de agregados de um Latossolo Vermelho-Amarelo. Revista Brasileira de Ciência do Solo, Viçosa, v. 37, n. 6, p. 1678-1688, 2013. Disponível em: <http://www.scielo.br/pdf/rbcs/v37n6/24.pdf>. Acesso em: 05 nov. 2017.

REICHERT, J. M.; REINERT, D. J.; BRAIDA, J. A. Qualidade dos solos e sustentabilidade de sistemas agrícolas. Ciência \& Ambiente, Santa Maria, v. 27, p. 29-48, jul./dez. 2003. Disponível em: <http:// www.fisicadosolo.ccr.ufsm.quoos.com.br/downloads/Producao_Artigos/5.pdf>. Acesso em: 02 nov. 2017.

REYNOLDS, W. D.; BOWMAN, B. T.; DRURY, C. F.; TAN, C. X.; LU, X. Indicators of good soil physical quality: density and storage parameters. Geoderma, v. 110, n. 1/2, p. 131-146, nov. 2002. Disponível em: <https://www.sciencedirect.com/science/article/pii/S0016706102002288>. Acesso em: 03 nov. 2017.

ROSA JUNIOR, E. J.; MARTINS, R. M. G.; ROSA, Y. B. C. J.; CREMON, C. Calcário e gesso como condicionantes físico e químico de um solo de cerrado sob três sistemas de manejo. Pesquisa Agropecuária Tropical, Goiânia, v. 36, n. 1, p. 37-44, 2006. Disponível em: <https://www.revistas.ufg. br/pat/article/view/2170>. Acesso em: 05 nov. 2017.

SÁ JUNIOR, A. de; CARVALHO, L. G. de; SILVA, F. F. da; ALVES, M. C. Application of the Köppen classification for climatic zoning in the state of Minas Gerais, Brazil. Theoretical and Applied Climatology, v. 108, n. 1, p. 1-7, apr. 2012. Disponível em: <https://link.springer.com/article/10.1007/ s00704-011-0507-8>. Acesso em: 01 nov. 2017.

SALTON, J. C. Agregação e estabilidade de agregados do solo em sistemas agropecuários em Mato Grosso do Sul. Revista Brasileira de Ciência do Solo, Viçosa, v. 32, n. 1, p. 11-21, jan./fev. 2008. Disponível em: <http://www.scielo.br/scielo.php?script=sci_arttext\&pid=S0100-06832008000100002>. Acesso em: 11 nov. 2017.

SÁ, M. A. C. de.; LIMA, J. M. de.; SILVA, M. L. N.; DIAS JUNIOR, M. D. S. Comparison of methods for aggregate stability studies in soils. Pesquisa Agropecuária Brasileira, Brasília, v. 35, n. 9, p. 1825-1834, Sept. 2000. Disponível em: <http://www.scielo.br/scielo.php?script=sci_arttext\&pi$d=$ S0100-204X2000000900015>. Acesso em: 06 nov. 2017.

SANTOS, H. G. dos; JACOMINE, P. K. T.; ANJOS, L. H. C. dos; OLIVEIRA, V. A. V.; LUMBRERAS, J. F.; COELHO, M. R.; ALMEIDA, J. A. de; CUNHA, T. J. F.; OLIVEIRA, J. B. de. Sistema brasileiro de classificação de solos. 3.ed. rev.ampl. Brasília, DF: Embrapa, 2013. 353p 
SILVA NETO, L. F. da.; SILVA, I. F. da.; INDA, A. V.; NASCIMENTO, P. C. do.; BORTOLON, L. Atributos físicos e químicos de agregados pedogênicos e de coprólitos de minhocas em diferentes classes de solos da Paraíba. Ciência \& Agrotecnologia, Lavras, v. 34, n. 6, p. 1365-1371, nov./dez. 2010. Disponível em: <http://www.scielo.br/scielo.php?pid=S1413-70542010000600002\&script=sci_abstract\&tlng=pt>. Acesso em: 06 jun. 2016.

THEODORO, V. C. A.; ALVARENGA, M. I. N.; GUIMARAES, R. J.; SOUZA, C. A. S. Alterações químicas em solo submetido a diferentes formas de manejo do cafeeiro. Revista Brasileira de Ciência do Solo, v. 27, n. 6, p. 1039-1047, 2003. Disponível em: <http://www.scielo.br/pdf/rbcs/v27n6/19198. pdf>. Acesso em: 05 nov. 2017.

\section{Histórico editorial:}

Submetido em: 23/05/2017.

Aceito em: 28/09/2017.

Como citar:

ABNT

Antunes, C. H. S; Portugal, L.; Maia, J. P.; Moreira, R. A.; Silva, B. M.;Santos, W. J. R. Diagnóstico da qualidade físico-química do solo sob diferentes usos e manejos no Sul de Minas Gerais. Revista Agrogeoambiental, Pouso Alegre, v. 10, n. 4, p. 27-40, dez. DOI: http://dx.doi.org/10.18406/2316-1817v10n420181225

APA

Antunes, C. H. S, Portugal, L., Maia, J. P., Moreira, R. A., Silva, B. M. \& Santos, W. J. R. (2018). Diagnóstico da qualidade físico-química do solo sob diferentes usos e manejos no Sul de Minas Gerais. Revista Agrogeoambiental, 10 (4), 27-40. DOI: http://dx.doi.org/10.18406/2316-1817v10n420181225

ISO

Antunes, C. H. S, Portugal, L., Maia, J. P., Moreira, R. A., Silva, B. M. e Santos, W. J. R. Diagnóstico da qualidade físico-química do solo sob diferentes usos e manejos no Sul de Minas Gerais. Revista Agrogeoambiental, 2018, vol. 10, n. 4, pp. 27-40. Eissn 2316-1817. Doi: http://dx.doi: 10.18406/2316$1817 v 10 n 420181225$

\section{VANCOUVER}

Antunes CHS, Portugal L., Maia, JP, Moreira, RA, Silva, BM, Santos, WJR. Diagnóstico da qualidade físicoquímica do solo sob diferentes usos e manejos no Sul de Minas Gerais. Revista Agrogeoambiental. 2018 dez.; 10(4): 27-40. DOI: http://dx.doi.org/10.18406/2316-1817v10n420181225 